This is the accepted manuscript of the following article:

Castrillo, M., Díez-Montero, R., Esteban-García, A. L., \& Tejero, I. (2019). Mass transfer enhancement and improved nitrification in MABR through specific membrane configuration. Water research, 152: 1-11.

The manuscript has been published in final form at:

https://doi.org/10.1016/i.watres.2019.01.001 


\title{
Mass transfer enhancement and improved nitrification in MABR through specific membrane configuration
}

Authors: M. Castrillo ${ }^{\mathrm{a},{ }^{*}}$, R. Díez-Montero, ${ }^{\mathrm{a}, \mathrm{b}}$, A.L. Esteban-García ${ }^{\mathrm{a}}$, I. Tejero ${ }^{\mathrm{a}}$

Affiliation:

${ }^{a}$ Environmental Engineering Group, Department of Science and Techniques of Water and the Environment. University of Cantabria. Santander, Spain.

${ }^{\mathrm{b}}$ Group of Environmental Engineering and Microbiology, Department of Civil and Environmental Engineering. Universitat Politècnica de Catalunya, Barcelona, Spain *Corresponding author: M. Castrillo

Tel: (+34)942 206711

Email address: castrillom@unican.es

\begin{abstract}
:
One of the main energy consumptions in wastewater treatment plants (WWTPs) is due to the oxygenation of aerobic biological processes. In order to approach to an energy selfsufficient scenario in WWTPs, Membrane Aerated Biofilm Reactors (MABRs) provide a good opportunity to reduce the impact of aeration on the global energy balance. However, mass transfer limitations derived from poor flow distribution must be tackled to take advantage of this technology. In this work, in order to improve mass transfer between biofilm and bulk water, a specific configuration was developed and studied at laboratory scale, aimed at compactness, energy efficiency and high nitrification rates. Nitrification rates were higher in the innovative configuration than in the conventional one, achieving a Volumetric Nitrification Rate (VNR) as high as $575.84 \mathrm{~g} \mathrm{NH}_{4}-\mathrm{N} \mathrm{m}^{-3} \mathrm{~d}^{-1}$, which is comparable with confirmed technologies. Regarding energy consumption due to aeration, a reduction of $83.7 \%$ was reached in comparison with aeration through diffusers with the same Oxygen Transfer Efficiency (OTE). These results highlight the importance of
\end{abstract}


hydrodynamic conditions and the membranes configuration on treatment performance.

Keywords: wastewater; nutrient removal; mass transfer; MABR; nitrification; energy self-sufficiency

Abbreviations:

Cs Saturation oxygen concentration

$\operatorname{mg~L^{-1}}$

HRT Hydraulic Retention Time

$\min$

$\mathrm{HRT}_{\mathrm{m}} \quad$ Mean Hydraulic Retention Time

$\min$

ID Inner diameter

$\mu \mathrm{m}$

$\mathrm{O}_{2 \text { inf }} \quad$ Dissolved oxygen in influent

$m g L^{-1}$

$\mathrm{O}_{2 \mathrm{ef}} \quad$ Dissolved oxygen in effluent

$m g L^{-1}$

OD Outer diameter

$\mu \mathrm{m}$

OOR Oxygen Outgoing Rate

$\mathrm{g} \mathrm{O}_{2} \mathrm{~m}^{-2}$

$d^{-1}$

OSR Oxygen Supply Rate

$\mathrm{g} \mathrm{O}_{2} \mathrm{~m}^{-2}$

$d^{-1}$

OTE Oxygen Transfer Efficiency

$\%$

OTR $_{\mathrm{bl}}$ Oxygen Transfer Rate calculated through measures in bulk water $\quad \mathrm{g} \mathrm{O}_{2} \mathrm{~m}^{-2}$

$d^{-1}$

$\mathrm{OTR}_{\mathrm{gp}}$ Oxygen Transfer Rate calculated through measures in gas phase

$\mathrm{g} \mathrm{O}_{2} \mathrm{~m}^{-2}$ $d^{-1}$ 
OUE $_{\mathrm{t}} \quad$ Oxygen Utilization Efficiency from the oxygen Transferred $\quad \%$

S Membrane surface

$\mathrm{m}^{2}$

SOTE Standard Oxygen Transfer Efficiency

$\%$

SOTR Standard Oxygen Transfer Rate $\quad \mathrm{g} \mathrm{O}_{2} \mathrm{~m}^{-2}$

$d^{-1}$

SNLR Specific Nitrogen (as $\left.\mathrm{NH}_{4}-\mathrm{N}\right)$ Loading Rate

g $\mathrm{NH}_{4}^{-}$

$\mathrm{N} \mathrm{m}^{-2} \mathrm{~d}^{1}$

SNR Specific Nitrification Rate

g $\mathrm{NH}_{4-}$

$\mathrm{N} \mathrm{m}^{-2} \mathrm{~d}^{-1}$

TSS Total Suspended Solids

$m g L^{-1}$

$\mathrm{K}_{\mathrm{L}} \mathrm{a}_{20} \quad$ Volumetric Mass Transfer Coefficient at $20^{\circ} \mathrm{C} \quad \mathrm{d}^{-1}$

$\alpha \quad$ Significance Level of Statistical Tests

\section{INTRODUCTION}

Membrane Aerated Biofilm Reactors (MABRs) for wastewater treatment show a huge potential to reduce the environmental and economic impacts of wastewater treatment plants (WWTPs). In MABRs, a biofilm grows on the outer side of gas permeable membranes. Oxygen is supplied to the inner part of the membranes and it diffuses from the lumen to the biofilm, while substrates diffuse from the wastewater to the outer side of the biofilm. This means that, in contrast to biofilm processes with conventional aeration, in MABRs oxygen and substrate transfer into the biofilm in opposite directions. It is this diffusion mechanism that allows for lower air flowrates and pressure, thus resulting in lower energy 
consumption. Thanks to this technology it is possible to save about $70 \%$ of aeration energy in comparison with fine bubble diffusers (Syron, 2014) and even more in comparison with coarse bubble diffusers (Soreanu et al., 2010). In addition, it provides high adaptability to variable conditions due to the easiness to control the factors that determine gas transfer, such as intramembrane pressure (Downing and Nerenberg, 2008) and periodic venting (Perez-Calleja et al., 2017). In spite of its recognised advantages that have made its incipient commercialization possible, some drawbacks still need to be tackled, especially mass transfer limitations that are among the key factors to achieve high efficiency in MABR.

In any biofilm process, in order to achieve high substrate removal rates, high available surface for biofilm is needed. This may be reached by designing high specific surface reactors. As an example, Moving Bed Biofilm Reactors (MBBR) are commonly designed with specific surfaces ranging from 500 to $1200 \mathrm{~m}^{2} \mathrm{~m}^{-3}$ depending on carrier characteristics (Barwal and Chaudhary, 2014). This is not the case of MABR, in which such high specific surfaces have led to poor performance. Packing density $(\% \mathrm{v} / \mathrm{v})$ and specific surface $\left(\mathrm{m}^{2} \mathrm{~m}^{-}\right.$ ${ }^{3}$ ) in experimental set-ups usually vary from 0.16 (Hwang, Cicek and Oleszkiewicz, 2009a) to 1.3 (Brindle, Stephenson and Semmens, 1998) and from 8.9 (da Silva et al., 2018) to 304 (Hwang, Cicek and Oleszkiewicz, 2009b) respectively.

The effect of packing density and membranes configuration on mass transfer has been intensively studied in hollow fibre contactors for oxygen stripping with porous membranes through mathematical modelling as well as experimental work. Among others, it has been concluded that the mass transfer coefficients in randomly packed modules can double those of uniformly-packed ones, which is attributed to the occurrence of transverse flow besides the theoretically predominant axial flow (Costello et al., 1993). It has been also stated that channelling and dead zones are the major phenomena that can take place on high packing modules (Wu and Chen, 2000). However, membranes in MABR show a relevant difference with hollow fibre contactors since a biofilm grows over them; therefore the flow pattern in 
the bulk liquid does not directly affect the gaseous phase mass transfer between the membrane and the biofilm. When the biofilm adheres to the membrane, there not practically exist a stagnant liquid layer between the membrane and the biofilm so the oxygen transfer is even greater than in absence of biofilm (Osa et al., 1997). Nevertheless, hydrodynamics continues playing a crucial role since solutes must diffuse from the bulk liquid to the biofilm going across the boundary layer formed over the biofilm, and the contribution of the resistance of the liquid boundary layer to the overall resistance is considerably higher than the resistance of the membrane when using thin silicone rubber membranes (PellicerNàcher et al., 2013). Concerning similar conclusions, it has been stated that further efforts to reduce the mass transfer resistance should be focused on improving the hydraulics of the membrane module (Côté, Bersillon and Huyard, 1989).

Proper flow pattern is essential to achieve high mass transfer rates and, therefore, high removal rates. Membranes layout not only affects the uniformity of flow velocity field, but also the local flow regime. The importance of fluid flow regime in MABR has been recently highlighted (Nerenberg, 2016). The occurrence of transverse flow giving place to convective transfer can improve reactor performance compared with only diffusion transfer occurrence (Ahmadi, Voller and Semmens, 2006). Wei et al. (2012) presented a reactor design to enhance flow velocity distribution with flow direction almost perpendicular to the membranes. In other work, residence time distribution has been experimentally studied at different recirculation flow rates and theoretical hydraulic retention times. It was stated that the higher the recirculation flow rate is, the more similar to full mixed flow pattern is achieved, but no data about membrane specific surface or packing density are given (Wang et al., 2012). With the aim of improving mixing in MABR, recent advances involving low energy consuming devices have been reported (Syron and Byrne, 2015).

In general, nowadays MABR are designed with the membranes in bundles, and bundles in rows. Depending on the specific arrangement, different packing densities and distributions may be found. Therefore different velocity fields appear in the reactor: while water velocity 
is high around the bundles resulting in channelling, low velocity and even stagnant volumes may take place inside the bundle as computational fluid dynamic (CFD) simulations have revealed (Plascencia-Jatomea et al., 2015; Kavousi et al., 2016). To date, MABR CFD simulations have been applied to homogeneously distributed straight membranes but, in spite of providing highly valuable and detailed information, its usefulness to design full scale reactors is still limited.

In this work a specific configuration was developed and studied at laboratory scale aimed at high compactness, energy efficiency and high nitrification rates. This configuration consists on a high packing reactor in which the opposite heads of the bundles are set closer than the length of the membranes, resulting in random membrane curvature and occupation of the whole cross section of the reactor. It was hypothesised that this configuration would reduce the thickness of the liquid boundary layer and, as a result, mass transfer would be enhanced. Furthermore, channelling would be avoided, or at least minimized due to the whole occupation of the cross section of the reactor. In addition, a compact bed could retain solid particles, which might avoid the need for secondary clarifier.

The general objective of this study was to elucidate the effect of the membranes configuration on the flow pattern and mass transfer properties at different mixing intensities to optimize mixing energy, which is one of the key factors to achieve energy efficient scalable configurations based on MABR.

\section{MATERIALS AND METHODS}

The feasibility of the specific, innovative configuration of the MABR previously described, was studied in comparison with a conventional one with more loosely and parallel fibre distribution. Comparison was made in terms of physical properties (flow pattern and mass transfer) as well as biological performance in a nitrification process. The effect of water velocity throughout the cross section of the reactor was also studied for both configurations testing with four different values: $1,5,10$ and $15 \mathrm{~m} \mathrm{~h}^{-1}$. They were achieved by different 
internal recirculation flow rates provided by a peristaltic recirculation pump (Cole Parmer Masterflex L/S). The lowest velocity is the equivalent to the velocity that would be provided by the raw wastewater feed flow rate plus a nitrate recirculation rate of $300 \%$ of the feed flow rate, without any other mixing system.

Regarding physical properties, flow pattern and mass transfer were assessed by means of tracer-response experiments with both bare and colonized membranes and dynamic oxygen transfer experiments in clean water respectively. After inoculation with activated sludge and treating synthetic wastewater, nitrification performance was studied in both configurations at the four water velocities. Oxygen transfer was monitored through the gas phase and the liquid phase in order to assess the influence of configuration and water velocity on Oxygen Transfer Rates (OTR) and Oxygen Transfer Efficiency (OTE) in bare membranes and colonized membranes.

\subsection{Experimental set-up}

This study was carried out in two laboratory-scale reactors in which the traditional configuration (R1) and the innovative one (R2) were implemented (Figure 1). $500 \mu \mathrm{m}(\mathrm{OD})$ x $300 \mu \mathrm{m}$ (ID) dense polydimethylsiloxane (PDMS) membranes were provided by Oxymem Ltd. 2000 membranes $0.5 \mathrm{~m}$ long were distributed in 4 equal bundles providing a total membrane surface of $1.57 \mathrm{~m}^{2}$. The reactor consisted on a rectangular vessel with section of $0.10 \times 0.07 \mathrm{~m}$ and $0.65 \mathrm{~m}$ high. The membranes were vertically placed and parallel to the axial axis of the reactor in R1 (Figure 1B). The same membranes were used in R2, but the inlet heads were set closer to the outlet heads, achieving a compact configuration where the membranes present deformations and curvatures and occupy the whole cross section of the reactor (Figure 1C). Specifically, the height of the module in R2 was $80 \%$ of the height of the module in R1. The water level was placed just above the upper heads, giving a specific surface of $453 \mathrm{~m}^{2} \mathrm{~m}^{-3}$ in $\mathrm{R} 1$ and $554 \mathrm{~m}^{2} \mathrm{~m}^{-3}$ in R2. Packing density calculated as the relation between the volume occupied by the membranes and the volume 
of the bed zone was 10.25 and $11.82 \%$ for $\mathrm{R} 1$ and $\mathrm{R} 2$ respectively.

(A)

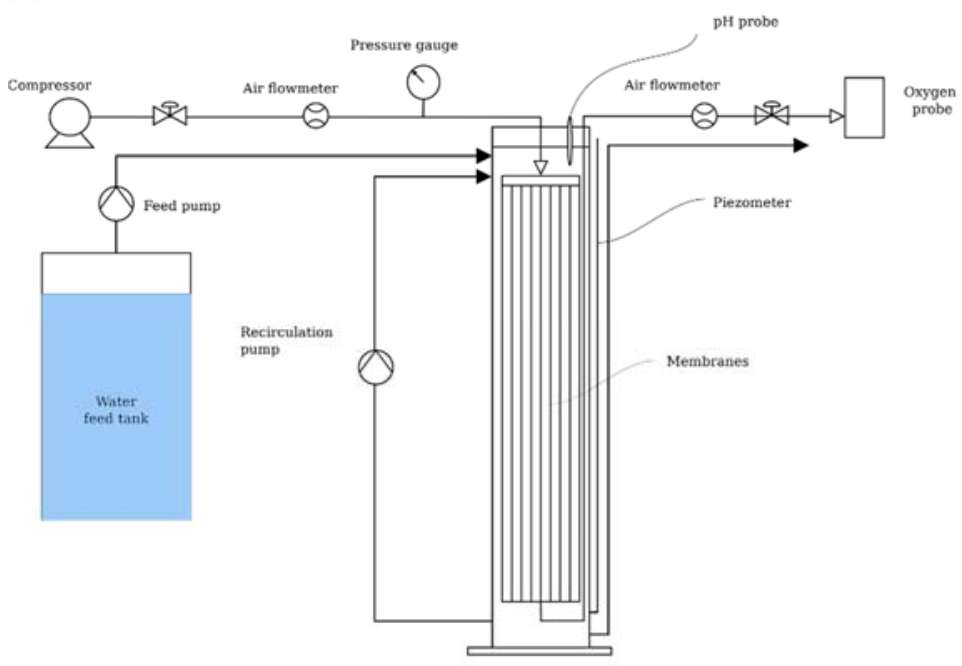

(B)

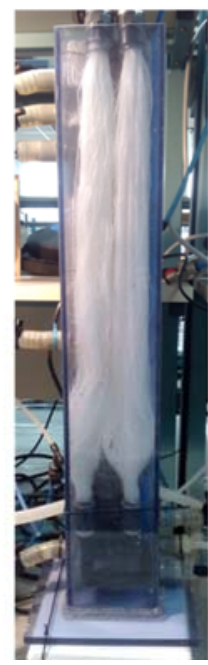

(C)

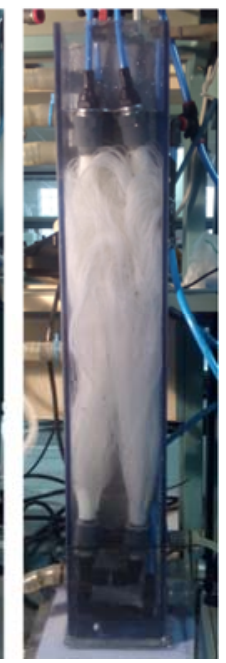

Figure 1. Reactor set-up diagram (A), picture of R1 (B) and picture of R2 (C).

In the reactor, water was continuously fed through a port located in the upper part of one of the narrower faces, just above the membrane bundles, while the outlet was placed in the opposite face below the membrane bundles. The reactor was operated in co-current mode, using ambient compressed air as gaseous phase. A valve was placed in the outlet of the air stream to regulate intramembrane pressure. The reactor was maintained at room temperature, which means that neither cooling nor heating were used. The average registered temperature is indicated for each specific experiment. A piezometer was placed on the bottom of the reactor; nonetheless no head loss was detected during the whole experimentation.

\subsection{Tracer-response experiments}

\subsubsection{Bare membranes and clean water}

A concentrated solution of sodium chloride $(\mathrm{NaCl})$ was introduced through pulse injection into the feed stream of the reactor. The amount of $\mathrm{NaCl}$ was calculated to have an initial concentration of $500 \mathrm{mg} \mathrm{L}^{-1}$ in the reactor supposing ideal complete mixing. The electrical 
conductivity of the outlet stream was monitored with an electrical conductivity probe (Hach IntelliCAL $\left.{ }^{\mathrm{TM}} \mathrm{CDC} 401\right)$, which was correlated to $\mathrm{NaCl}$ concentration. The theoretical hydraulic retention time (HRT) was $129 \mathrm{~min}$ and the experiments lasted at least three HRT.

The residence time distribution (RTD) functions were calculated as in Equation (1), where $\mathrm{E}(\mathrm{t})$ is the fraction of fluid that spends a time $t$ in the reactor $\left(\min ^{-1}\right), \mathrm{C}(\mathrm{t})$ is the tracer concentration in the outlet stream at a time $t\left(\mathrm{mg} \mathrm{L}^{-1}\right)$, and $t$ is the running time (min).

$$
E(t)=\frac{C(t)}{\int_{0}^{\infty} C(t) d t}
$$

The mean hydraulic retention time $\left(\mathrm{HRT}_{\mathrm{m}}\right)$ was calculated as:

$$
H R T_{m}=\int_{0}^{\infty} t E(t) d t
$$

\subsubsection{Colonized membranes and synthetic wastewater}

Additional tracer tests were performed after several weeks of operation treating synthetic wastewater, once steady-state conditions were achieved. In this case, lithium chloride $(\mathrm{LiCl})$ was used as tracer since the composition of synthetic wastewater could interfere with the conductivity signal. A concentrated solution of $\mathrm{LiCl}$ was introduced through pulse injection into the feed stream of the reactor and samples were taken in the outlet stream during three HRT at times (minutes): 0 (just before the injection), 3, 6, 9, 12, 15, 30, 45, 60 and then every 30 minutes until minute 390 (three HRT). $\mathrm{LiCl}$ in the pulse was calculated to have an initial concentration of $5 \mathrm{mg} \mathrm{Li}^{+} \mathrm{L}^{-1}$ in the reactor supposing ideal complete mixing. $\mathrm{Li}^{+}$concentration was determined in the samples using Flame Atomic Absorption Spectrophotometry (Perkin Elmer AAnalyst 300). Data were treated by means of equations (1) and (2).

\subsection{Oxygen transfer experiments}

\subsubsection{Bare membranes and clean water}


The tests were carried out by re-oxygenating water after oxygen removal through sodium sulphite oxidation. Water was deoxygenated in an external vessel to assure homogeneous mixing and then it was transferred into the reactor. This avoids oxygen depletion in the gas line and back diffusion of nitrogen during water deoxygenation, which would have led to erroneous data at the beginning of the tests. The tests commenced immediately after pouring the water into the tank. The air mass flow rate demand was determined according to the stoichiometry of the nitrification reaction. Taking into account the stoichiometry of the nitrification reaction, 4.57 grams of oxygen are needed for every gram of ammonium nitrogen. Considering as design criteria a Specific Nitrification Rate (SNR) of $1 \mathrm{~g} \mathrm{NH}_{4}-\mathrm{N}$ $\mathrm{m}^{-2} \mathrm{~d}^{-1}$ and a minimum OTE of $20 \%$, a minimum air mass flow rate of $0.113 \mathrm{~g}$ air $\mathrm{min}^{-1}$ is needed. Inlet air pressure was $12 \mathrm{kPa}$ (relative) and water temperature was $20.9 \pm 0.8^{\circ} \mathrm{C}$.

Oxygen transfer was evaluated by two methods: through measurements in the bulk liquid $\left(\mathrm{OTR}_{\mathrm{bl}}\right)$ and through measurements in the gas phase $\left(\mathrm{OTR}_{\mathrm{gp}}\right)$. For the first case, the procedure based on the ASCE standard (ASCE, 1994) was implemented. Oxygen concentration and temperature were monitored in water by means of a luminescent oxygen probe (Hach IntelliCAL ${ }^{\text {TM }}$ LDO101), that was placed in the upper part of the reactor, above the membranes. $\mathrm{K}_{\mathrm{L}} \mathrm{a}_{20}$ and saturation oxygen concentration $(\mathrm{Cs})$ were calculated from nonlinear regression method using the software Curve Expert 1.4 (Hyams Development) and corrected to $20^{\circ} \mathrm{C}$. Standard OTR $\mathrm{Ol}_{\mathrm{bl}}\left(\mathrm{SOTR}_{\mathrm{bl}}\right)\left(\mathrm{g} \mathrm{O}_{2} \mathrm{~m}^{-2} \mathrm{~d}^{-1}\right)$ was calculated as in equation (3), where $K_{L} a_{20}$ is the oxygen volumetric mass transfer coefficient at $20^{\circ} \mathrm{C}\left(\mathrm{d}^{-1}\right), \mathrm{Cs}_{20}$ is the saturation oxygen concentration at $20^{\circ} \mathrm{C}\left(\mathrm{mg} \mathrm{L}^{-1}\right)$ and $\mathrm{V}$ is the reactor water volume (L). SOTR $\mathrm{bl}$ was normalized to membrane surface by dividing by the total membrane surface $(\mathrm{S})\left(\mathrm{m}^{2}\right)$.

$$
\operatorname{SOTR}_{b l}=\frac{K_{L} a_{20} \cdot C S_{20} \cdot V}{S \cdot 1000}
$$

For the second case, oxygen transfer was evaluated through monitoring of air mass flow rate with mass flowmeters (Bürkert MFM type 8701) and oxygen concentration in the 
outlet gas stream by means of a galvanic oxygen probe (Oxyguard Atlantic Oxygen Meter). The oxygen mass balance of equation (4) allows calculating the $\mathrm{OTR}_{\mathrm{gp}}\left(\mathrm{mg} \mathrm{O}_{2} \min ^{-1}\right)$, where OSR is the oxygen supply rate $\left(\mathrm{mg} \mathrm{O}_{2} \mathrm{~min}^{-1}\right)$ and OOR is the oxygen outgoing rate $\left(\mathrm{mg} \mathrm{O}_{2} \mathrm{~min}^{-1}\right)$. OSR is calculated considering that inlet air stream contains $20.95 \%(\mathrm{v} / \mathrm{v})$ while OOR is calculated from the registered oxygen concentrations in the outlet gas stream. Results were normalized to the total membrane surface area.

$$
O T R_{g p}=O S R-O O R
$$

OTE (\%) was determined as the ratio between $\mathrm{OTR}_{\mathrm{gp}}$ and OSR.

$$
O T E=\frac{O T R_{g p}}{O S R} \times 100
$$

\subsubsection{Oxygen Transfer and Utilization Efficiency characterization during nitrification}

During the whole nitrification experimental period, the gas phase as well as oxygen concentration in water were monitored as in section 2.3.1. Intramembrane pressure was $11.8 \pm 0.2 \mathrm{kPa}$ (relative) and specific air mass flow rate was $0.111 \pm 0.001 \mathrm{~g}^{\text {air }} \mathrm{m}^{-2} \mathrm{~min}^{-1}$. OTR $_{\mathrm{gp}}$ based on gas measurements was calculated through the oxygen mass balance in equation 4. Average water temperature was $22.3 \pm 1.0^{\circ} \mathrm{C}$.

Utilized oxygen was calculated stoichiometrically from nitrite and nitrate produced in each experimental condition. Dissolved oxygen in the influent $\left(\mathrm{O}_{2 \text { inf }}\right)$ accounted for only $0.6 \%$ of the total oxygen supply to the system, therefore it was considered negligible. Oxygen coming from $\mathrm{CO}_{2}$ reduction was not taken into account. Then, Oxygen Utilization Efficiency (OUE (\%)) was calculated as the rate between utilized oxygen and supplied oxygen, that represents the fraction of oxygen consumed for nitrification from the oxygen supplied to the system (shown in equation 6, where Q is the water flow rate). It was also calculated the oxygen utilization efficiency from the oxygen transferred by the membranes, 
named $\mathrm{OUE}_{\mathrm{t}}$ (Equation 7).

$$
\begin{gathered}
O U E=\frac{Q \cdot\left(3.42 \cdot \mathrm{NO}_{2}-\mathrm{N}+4.57 \cdot \mathrm{NO}_{3}-\mathrm{N}\right)}{O S R} \\
O U E_{t}=\frac{O U E}{O T E}
\end{gathered}
$$

Energy consumption was calculated according to the equation given in Metcalf and Eddy (2004) for the power requirement for compression.

\subsection{Nitrification performance}

The reactors were inoculated with 3.3 L of diluted activated sludge (Total Suspended Solids $(\mathrm{TSS})=756 \mathrm{mg} \mathrm{L}^{-1}$ ) from the aerobic tank of a local WWTP. The reactor was fed by an electromagnetic dosing pump (Seko AKS 603), with synthetic wastewater prepared with tap water and the following composition $\left(\mathrm{mg} \mathrm{L}^{-1}\right)$ : $\mathrm{NH}_{4} \mathrm{Cl}, 230 ; \mathrm{KH}_{2} \mathrm{PO}_{4}, 53 ; \mathrm{MgSO}_{4} \cdot 7 \mathrm{H}_{2} \mathrm{O}$, 605; $\mathrm{CaCl}_{2} \cdot 2 \mathrm{H}_{2} \mathrm{O}, 71$; and trace elements solution: $\mathrm{FeCl}_{3} \cdot 6 \mathrm{H}_{2} \mathrm{O}, 3.03 ; \mathrm{H}_{3} \mathrm{BO}_{3}, 0.30$; $\mathrm{CuSO}_{4} \cdot 5 \mathrm{H}_{2} \mathrm{O}, 0.06 ; \mathrm{KI}, 0.06 ; \mathrm{MnCl}_{2} \cdot 4 \mathrm{H}_{2} \mathrm{O}, 0.24 ; \mathrm{Na}_{2} \mathrm{MoO}_{4} \cdot 2 \mathrm{H}_{2} \mathrm{O}, 0.12 ; \mathrm{ZnSO}_{4} \cdot 7 \mathrm{H}_{2} \mathrm{O}$ 0.24 and $\mathrm{CoCl}_{2} \cdot 6 \mathrm{H}_{2} \mathrm{O}, 0.30$. Alkalinity was added stoichiometrically as $\mathrm{NaHCO}_{3}$ taking into account that $7.14 \mathrm{~g}$ of alkalinity as $\mathrm{CaCO}_{3}$ are needed per gram of nitrified $\mathrm{NH}_{4}-\mathrm{N}$. Therefore, total nitrogen concentration was $60.2 \mathrm{mg} \mathrm{N} \mathrm{L}^{-1}$ and total phosphorus concentration was $12 \mathrm{mg} \mathrm{P} \mathrm{L}^{-1}$, providing a N:P ratio of 5 .

During the experimentation the SNLR was maintained at $1.37 \pm 0.41 \mathrm{~g} \mathrm{NH}_{4}-\mathrm{N} \mathrm{m}^{-2} \mathrm{~d}^{-1}$. Variations were due to fluctuations in the dosing pumps flow rate. HRT was $128 \pm 7.2$ minutes.

Start-up stage lasted three months in which nitrogen load increased gradually by decreasing hydraulic retention time (HRT) and rising ammonium nitrogen $\left(\mathrm{NH}_{4}-\mathrm{N}\right)$ concentration in the influent synthetic water. Specific measurements to study the influence of membranes layout and water velocity were carried out once stable conditions were achieved. Operational variables such as HRT, influent air mass flow rate, specific ammonium 
nitrogen loading rate (SNLR) and intramembrane pressure were established equal than in the physical characterization experiments in order to obtain comparable results.

To assure steady-state conditions between different experiments, each experimental condition ran during at least 10 HRTs. Three samples were taken during each experiment and each sample was analysed twice, so in total six samples were taken per experiment for chemical analyses. Nitrogen as ammonium, nitrite and nitrate $\left(\mathrm{NH}_{4}-\mathrm{N}, \mathrm{NO}_{2}-\mathrm{N}\right.$ and $\left.\mathrm{NO}_{3}-\mathrm{N}\right)$ were monitored by photometric analyses using a spectrophotometer Spectroquant ${ }^{\circledR}$ Pharo 300 (MERCK) from filtered samples (Whatman paper filter GF/C $1.2 \mu \mathrm{m}$ ). Total Suspended Solids were determined to control the presence of particles from biofilm detachment in the effluent. Samples were filtered with Whatman paper filter GF/C $1.2 \mu \mathrm{m}$ and dried at $105^{\circ} \mathrm{C}$ until constant weight. $\mathrm{pH}$ was continuously monitored with Crison Instruments sensor 5333, remaining at an average value of $6.79 \pm 0.25$ (due to the aforementioned addition of alkalinity). The reactor was maintained at room temperature and monitored daily, resulting in $22.3 \pm 1.0^{\circ} \mathrm{C}$.

\subsection{Statistical analyses}

Statistical analyses of the data were carried out with the software IBM SPSS Statistic Subscription. Results were considered highly significant when significance level $(\alpha) \leq 0.01$ and significant if $0.01<\alpha \leq 0.05$. In order to compare results, data were analysed with tStudent or ANOVA and Tukey's HSD post hoc analyses as parametric tests. Significance values of the tests are presented in the Appendix. In this text, it is said that there exist differences between two groups of measures when these differences are statistically significant or highly significant. Otherwise, it is said that there are no differences. In charts, error bars show $95 \%$ confidence intervals of the mean.

\section{RESULTS AND DISCUSSION}

\subsection{Flow pattern characterization}




\subsubsection{Bare membranes with clean water}

The RTDs with $\mathrm{NaCl}$ as tracer using clean water and bare membranes were calculated according to Equation (1) for the two compared configurations and four water velocities.

In Figure 2, the tracer concentration versus time for each situation is presented. They allow identifying a very high peak at the beginning of the experiments at $1 \mathrm{~m} \mathrm{~h}^{-1}$ followed by a pronounced slope in both configurations. The peak over-passed the tracer concentration calculated for complete mixing conditions in 201 and $166 \%$ in R1 and R2 respectively. In the moment that the peak was detected, it had been recovered $4.75 \%$ and $3.51 \%$ of the tracer mass respectively. In order to assure that these peaks where due to short-circuits and not because of the occurrence of density currents, some tests were made at lower tracer concentration (100 mg L $\mathrm{m}^{-1}$ ) and similar results were obtained (in $\mathrm{R} 2$ at $1 \mathrm{~m} \mathrm{~h}^{-1}$ the peak reached $254 \%$ of the concentration calculated for complete mixing conditions and the percentage of tracer recovered in that moment was $3.21 \%$ ). At intermediate velocities (5 and $10 \mathrm{~m} \mathrm{~h}^{-1}$ ) the hydraulic behaviours were close to those characteristic of a fully mixed tank in both configurations, with less sharpen peaks and steeper slopes. At these two velocities, the tracer concentration at the beginning was very close to the theoretical one. However, the initial peak was more pronounced in $\mathrm{R} 1$. At $15 \mathrm{~m} \mathrm{~h}^{-1}$ a high peak was identified in R1 while in R2 the concentration curve maintained the shape close to the fully mixed pattern. 

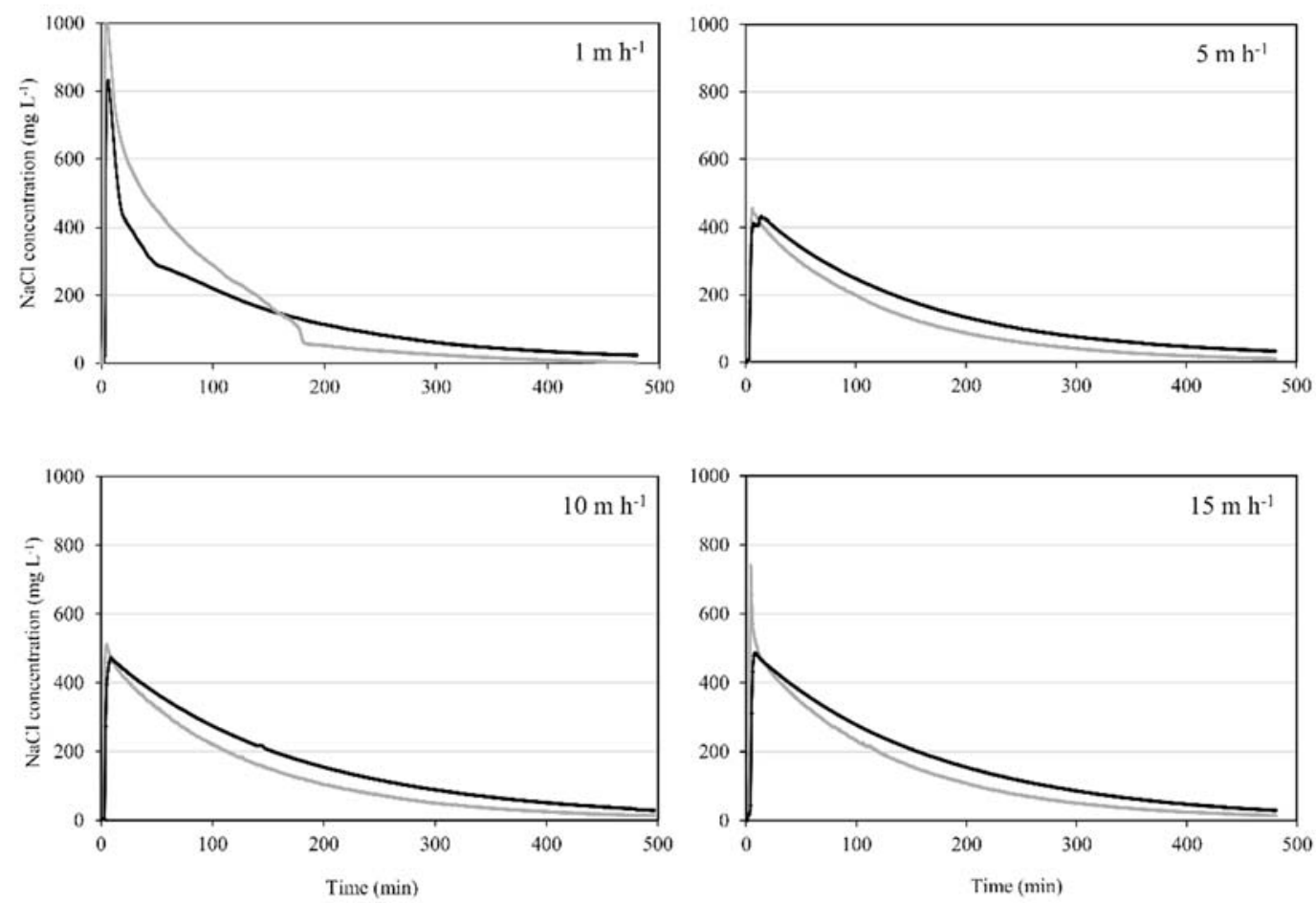

Figure 2. Tracer concentration ( $\mathrm{mg} \mathrm{NaCl} \mathrm{L}^{-1}$ ) versus time (min) in $\mathrm{R} 1(\diamond)$ and $\mathrm{R} 2(\diamond)$ for

the tested water velocities, in experiments with clean water and bare membranes.

HRTm was lower than the theoretical one (129 min) in all the experiments in R1 (84.23, $115.08,122.37$ and 117.99 minutes from $1,5,10$ and $15 \mathrm{~m} \mathrm{~h}^{-1}$ respectively), while in $\mathrm{R} 2$ it was slightly higher than the theoretical one, except for the lowest velocity $(128.06,142.12$, 147.33, and 141.60 minutes from $1,5,10$ and $15 \mathrm{~m} \mathrm{~h}^{-1}$ respectively).

These results highlight the importance of hydrodynamics in this kind of reactors. On the one hand, low velocities do not produce enough hydraulic resistance to force the flow to go through narrow and tortuous conducts. On the other hand, a higher energy investment to reach high velocities not only may be worthless, what is more, it can be detrimental. According to these results, the traditional configuration is more prone to produce shortcircuits, giving place to peaks of concentration higher than the maximum achievable concentration considering fully mixing, while the innovative configuration shows a profile that matches a fully mixed tank model from 5 to $15 \mathrm{~m} \mathrm{~h}^{-1}$.

\subsubsection{Colonized membranes with synthetic wastewater}


When the flow pattern was studied in presence of biofilm, the concentration profiles were similar to those obtained with bare membranes (Figure 3), but showing more pronounced peaks. The only situations in which a sharp peak was not observed at the beginning of the test were at velocities of 5 and $10 \mathrm{~m} \mathrm{~h}^{-1}$ in R2. Furthermore, in these situations the initial tracer concentration was very close to the theoretical one $\left(5 \mathrm{mg} \mathrm{Li}^{+} \mathrm{L}^{-1}\right)$. Velocities of 1 and $15 \mathrm{~m} \mathrm{~h}^{-1}$ presented the peaks suggesting the occurrence of short-circuits or canalization with too low or high velocities also in R2. It could be said that the situation found with bare membranes is accentuated when the biofilm has grown over it. These results suggest that the presence of biomass produces additional hydraulic resistance due to the filling of the conducts. It is coherent with the hypothesis that in the traditional configuration, increasing the hydraulic resistance leads to a preferential circulation through wider conducts, which is detrimental for the performance. However, in the innovative one, flow pattern is similar than in absence of biomass within a certain range of velocities due to the homogeneity of the width in the conducts.
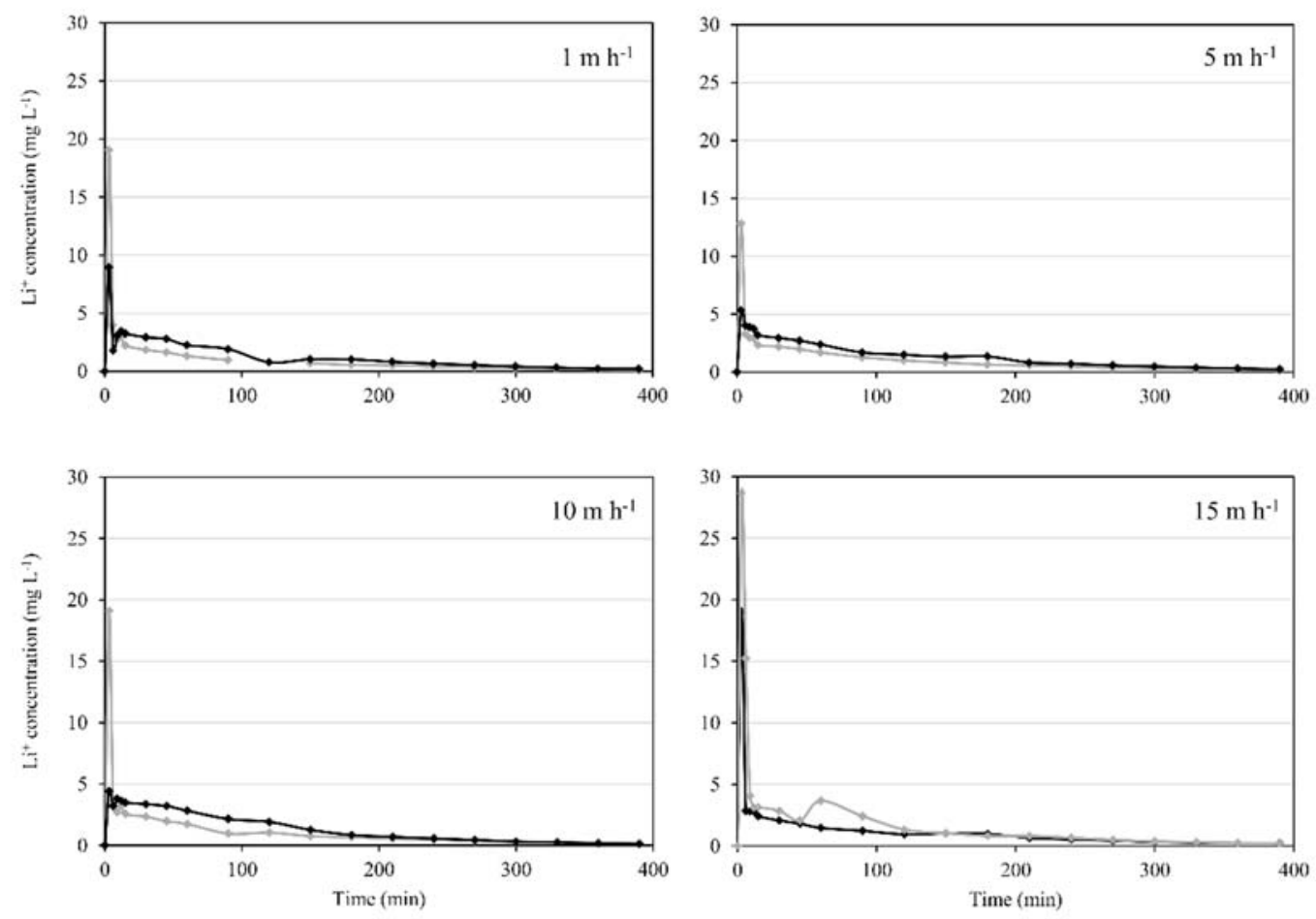

Figure 3. Tracer concentration (mg Li+ L-1) versus time (min) in R1 ( $)$ and in R2 ( $)$ for 
the tested water velocities, in experiments with synthetic wastewater and colonized

membranes.

\subsection{Oxygen transfer characterization}

\subsubsection{Oxygen transfer with bare membranes and clean water}

According to flow pattern results in clean water, the tests at the lowest velocity in both reactors and at the highest velocity in $\mathrm{R} 1$ show a deviation from a fully mixed tank pattern. Therefore, spatial variations in these situations are expected to affect the $\mathrm{K}_{\mathrm{L}}$ a determination. As shown in Figure $4 a$ and $4 b$, in $R 1$ raising the water velocity always resulted in an increase of the $\mathrm{K}_{L} \mathrm{a}_{20}$ and the specific OTR $\mathrm{bl}_{\mathrm{b}}$. The increasing in $\mathrm{K}_{\mathrm{L}} \mathrm{a}_{20}$ and OTR $\mathrm{O}_{\mathrm{b} 1}$ with water velocity could be attributed to the liquid boundary layer reduction due to the increasing in mixing intensity. An optimum was not reached within this range of velocities, which suggests that probably an $\mathrm{OTR}_{\mathrm{bl}}$ equal or higher than the maximum obtained for $\mathrm{R} 2$ could be achieved, but at the expense of higher energy consumption. In R2, from $10 \mathrm{~m} \mathrm{~h}^{-1}$, higher velocity did not result in better results. $K_{L} a_{20}$ in $R 2$ was always higher than in $R 1$, in fact, even at $5 \mathrm{~m} \mathrm{~h}^{-1}$ it was higher than at all the velocities tested in $\mathrm{R} 1$.

According to Figure $4 \mathrm{~b}, \mathrm{OTR}_{\mathrm{bl}}$ seems to present lower differences between both configurations than $\mathrm{K}_{\mathrm{L}} \mathrm{a}_{20}$, being almost equal at the highest and at the lowest velocities. Nonetheless, the highest $\mathrm{OTR}_{\mathrm{bl}}$ was achieved with the innovative configuration, and this $\mathrm{OTR}_{\mathrm{bl}}$ was not reached with the traditional one even at higher velocity. Taking into account the results of the tracer-response experiments, the enhancement at intermediate velocities in the innovative configuration may be attributed to the overall effect of a better flow pattern as well as to the reduction of the liquid boundary layer. This better flow pattern can have different effects: on the one hand there is more membrane surface exposed to the bulk liquid due to the reduction of channelling, while on the other hand solutes are better distributed in the bulk liquid. The latter is more evident when the oxygen is measured in 
the bulk liquid. When the flow pattern is not proper, solutes may find difficulties to diffuse homogeneously and to arrive to the probe. Therefore, this effect is not so evident when the oxygen is measured in the gas phase.
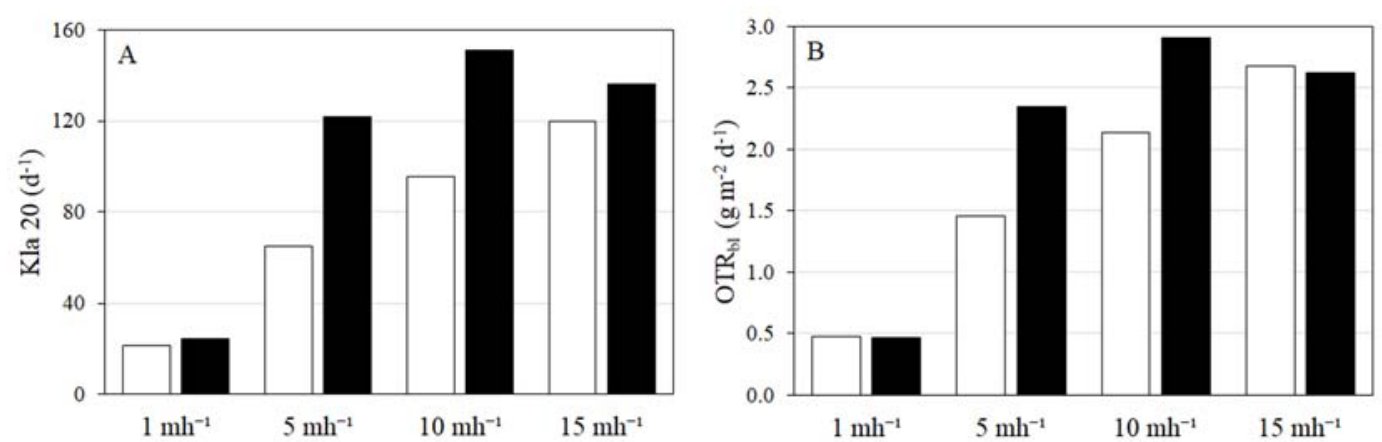

Figure 4. A. $\mathrm{K}_{\mathrm{L}} \mathrm{a}_{20}\left(\mathrm{~d}^{-1}\right)$ and B. specific OTR $\mathrm{Ol}_{\mathrm{bl}}\left(\mathrm{g} \mathrm{O}_{2} \mathrm{~m}^{-2} \mathrm{~d}^{-1}\right)$ at the tested water velocities in R1 ( $\square$ ) and in R2 ( $\mathbf{a})$.

$\mathrm{OTR}_{\mathrm{gp}}$ was always higher than OTR $\mathrm{bl}$, independently of the configuration. As an example the representation of OTR as a function of dissolved oxygen for experiments at $10 \mathrm{~m} \mathrm{~h}^{-1}$ is shown in Figure 5. Oxygen bubbles were formed on the surface of the membranes, especially at low mixing intensities, which may mean that the liquid boundary layer gets oxygenated faster than the bulk liquid. This suggests that there is a lag in bulk water oxygenation with respect to membrane transfer. This lag is also intuited in the first part of the graph in Figure 5, at DO $<2 \mathrm{mg} \mathrm{L}^{-1}$. Although OTR is expectable to take its maximum value at low DO concentrations, this cannot be observed when measures for oxygen transfer characterization are taken in bulk water. The deviation from linearity with respect to measures taken in the gas stream may be explained as the delay of bulk water oxygenation due to mixing properties. 


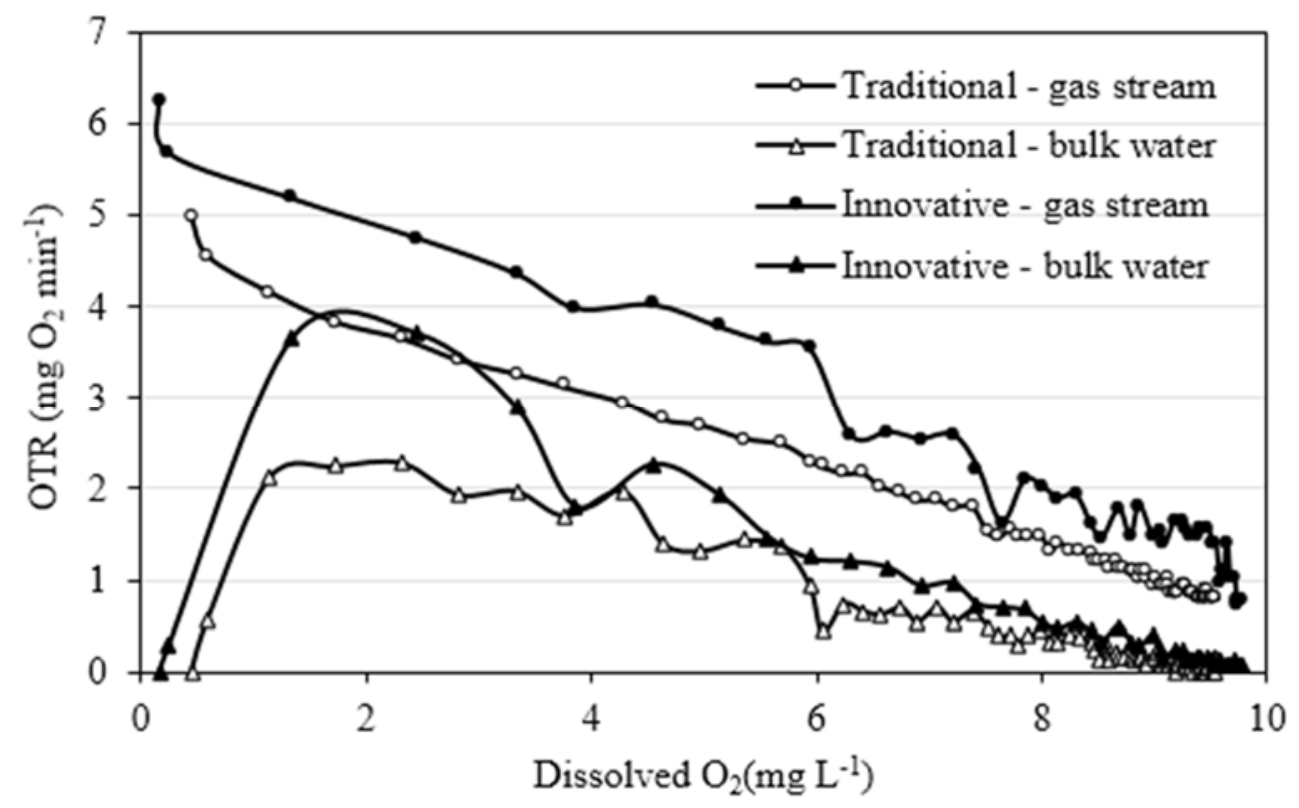

Figure 5. OTR $\left(\mathrm{mg} \mathrm{O}_{2} \mathrm{~min}^{-1}\right)$ in experiments at $10 \mathrm{~m} \mathrm{~h}^{-1}$ obtained from gas stream (circles) and from water (triangles) in the traditional and the innovative configuration, as a function of dissolved oxygen $\left(\mathrm{mg} \mathrm{O}_{2} \mathrm{~L}^{-1}\right)$.

\subsubsection{Oxygen transfer and utilization efficiency with bare and colonized membranes}

In order to compare OTR in clean water and under biological operation, during nitrification the gas line was monitored in the same way than in the oxygenation tests. As it can be observed in Figure 5, OTR determined through the gas stream as a function of dissolved oxygen in water follows a linear trend. Therefore, the linear function for each situation was obtained and the maximum OTR $_{\mathrm{gp}}$ was determined as its value when dissolved oxygen in water was $0 \mathrm{mg} \mathrm{L}^{-1}$. The values of maximum OTR $\mathrm{gp}$ and OTR in biological experimentation are presented in Figure 6. As a general rule, in oxygenation tests, OTR always increased with water velocity. However, in biological operation OTR followed this trend only between 1 and $10 \mathrm{~m} \mathrm{~h}^{-1}$, but at $15 \mathrm{~m} \mathrm{~h}^{-1}$, OTR decreased to 74 and $93 \%$ of OTR at $10 \mathrm{~m} \mathrm{~h}^{-}$ ${ }^{1}$ for the traditional and the innovative configuration respectively. This could be explained by the fact that, with bare membranes, high water velocity contributes to a reduction of the 
boundary layer between the membrane and the bulk water and OTR is enhanced, but in presence of biofilm, the reduction of the liquid boundary layer does not directly affect the oxygen transfer, but the interchange of solutes (i.e. $\mathrm{NH}_{4} \mathrm{~N}$ ). The tracer experiments revealed that the highest velocity was detrimental for the flow pattern in the reactor. Therefore, although higher velocity could be producing higher oxygen mass-transfer between the membranes and the boundary layer in absence of biofilm, as the results of OTR $_{g p}$ reveal, the distribution of the solutes in the bulk liquid is not appropriate to allow the enhancement of mass transfer between the membrane and the biofilm.

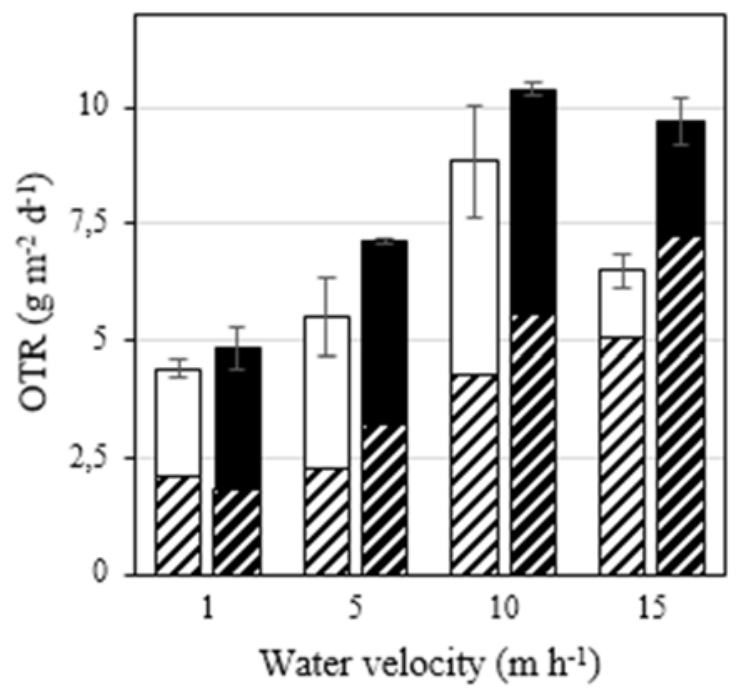

Figure 6. OTR $\left(\mathrm{g} \mathrm{O}_{2} \mathrm{~m}^{-2} \mathrm{~d}^{-1}\right)$ in $\mathrm{R} 1$ (white background) and in $\mathrm{R} 2$ (black background) at the tested water velocities, measured under biological operation (plain) and calculated from oxygen transfer characterization tests for $\mathrm{DO}=0 \mathrm{mg} \mathrm{L}^{-1}$ (stripes) ( $\bullet$ Error bars represent $95 \%$ confidence intervals of the mean.

In biological operation OTR was between 1.29 and 2.64 times higher than OTR $_{\mathrm{gp}}$ in oxygenation tests. The highest absolute augmentation occurred at $10 \mathrm{~m} \mathrm{~h}^{-1}$, followed by 5 $\mathrm{m} \mathrm{h}^{-1}$ and finally the lowest augmentation occurred at 1 and $15 \mathrm{~m} \mathrm{~h}^{-1}$ in both configurations. In R1, under biological operation no differences in OTR were found between 1 and $5 \mathrm{~m} \mathrm{~h}^{-}$ ${ }^{1}$ and between 5 and $15 \mathrm{~m} \mathrm{~h}^{-1}$, but highly significant differences appeared between all the 
other possibilities. In R2, the differences between the assayed velocities were less remarkable. Between 1 and $5 \mathrm{~m} \mathrm{~h}^{-1}$ and between 10 and $15 \mathrm{~m} \mathrm{~h}^{-1}$ no differences were found, but they appeared between all the other couples, although with less significance than in R1. Significant differences between both configurations only were found at $15 \mathrm{~m} \mathrm{~h}^{-1}$, meaning that, taking into account only oxygen mass balances in the gas phase it cannot be concluded that the innovative configuration significantly enhances the mass transfer in MABR. The significance values of the Student's T-test and Tukey's HSD test belonging to this analysis are shown in Appendix section A.1.

Regarding OTE, in oxygen transfer characterization with clean water and bare membranes it ranged from 4.36 to $14.30 \%$, being higher in R2 except for the lowest water velocity, where it was almost equal than in R1 (Figure 7). Since OSR was always the same, OTE in biological experimentation followed the same trend with respect to water velocity than OTR. The maximum OTE reached was $27.89 \%$, which was achieved without implementing optimization strategies in the gas line, like venting (Perez-Calleja et al., 2017), since its optimization was not the aim of this work. It took place at $10 \mathrm{~m} \mathrm{~h}^{-1}$ in the compact configuration. In the MABR technology the OTE with biofilm is higher than the one measured with clean water, due to the driving force produced by the biofilm. This is a particular difference with conventional activated sludge systems, where the OTE in operation is lower than the OTE measured with clean water. 


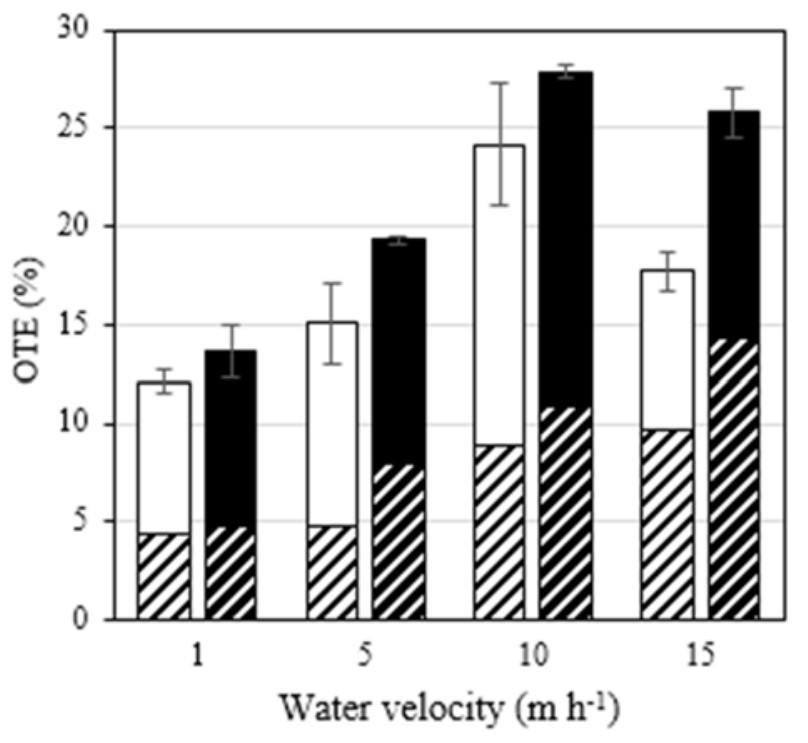

Figure 7. Oxygen Transfer Efficiency (\%) in R1 (white background) and in R2 (black background) at the tested water velocities, measured under biological operation (plain) and in oxygenation tests with clean water and bare membranes through measures in the gas phase (striped). Error bars represent $95 \%$ confidence intervals of the mean.

The oxygen transfer efficiency per unit energy in the experimental conditions of this work, takes the value of $19.6 \mathrm{~kg} \mathrm{O}_{2} \mathrm{kWh}^{-1}$. The OTE of $27.89 \%$ is in the upper range of standard OTE (SOTE) reported for different diffuser systems at $4.5 \mathrm{~m}$ column water submergence (Metcalf and Eddy, 2004); however diffuser systems require a pressure to overcome the water column and friction losses. Furthermore, OTE of porous diffusers is known to significantly decrease under process conditions, on the contrary than in MABR. There are several factors that reduce OTE with respect to SOTE (i.e. surface tension, temperature, clogging, etc.). Taking typical values of the corrector factors (Metcalf and Eddy, 2004), a reduction of at least $30 \%$ is expectable. With the resulting OTE, considering fine bubble diffusers, oxygen transfer efficiency per unit energy would be $3.19 \mathrm{~kg} \mathrm{O}_{2} \mathrm{kWh}^{-1}$. In other words, a reduction of $83.7 \%$ in energy consumption for aeration is possible by making use of MABR technology with the appropriate physical configuration. 
Not all the oxygen supplied was utilized in nitrification; therefore OUE and $\mathrm{OUE}_{\mathrm{t}}$ were calculated according to Equations (6) and (7) and presented in Figure 8. OUE $E_{t}$ did not present significant differences between both configurations at the tested velocities, but the highest significance occurred at $10 \mathrm{~m} \mathrm{~h}^{-1}(\alpha=0.068)$. In the case of the traditional configuration, the increase of water velocity resulted in the rise of OTR, but not in a higher oxygen utilization, therefore $\mathrm{OUE}_{\mathrm{t}}$ decreased between 1 and $10 \mathrm{~m} \mathrm{~h}^{-1}$. Significant differences occurred only between 1 and $10 \mathrm{~m} \mathrm{~h}^{-1}$. Regarding the compact configuration, $\mathrm{OUE}_{\mathrm{t}}$ was maintained almost constant for all the water velocities tested, in fact, no significant differences appeared between different velocities. Consequently, OUE is not improved when raising the water velocity in the traditional configuration, on the contrary than in the innovative one, where $\mathrm{OUE}_{\mathrm{t}}$ is practically constant and therefore OUE is proportional to OTR.

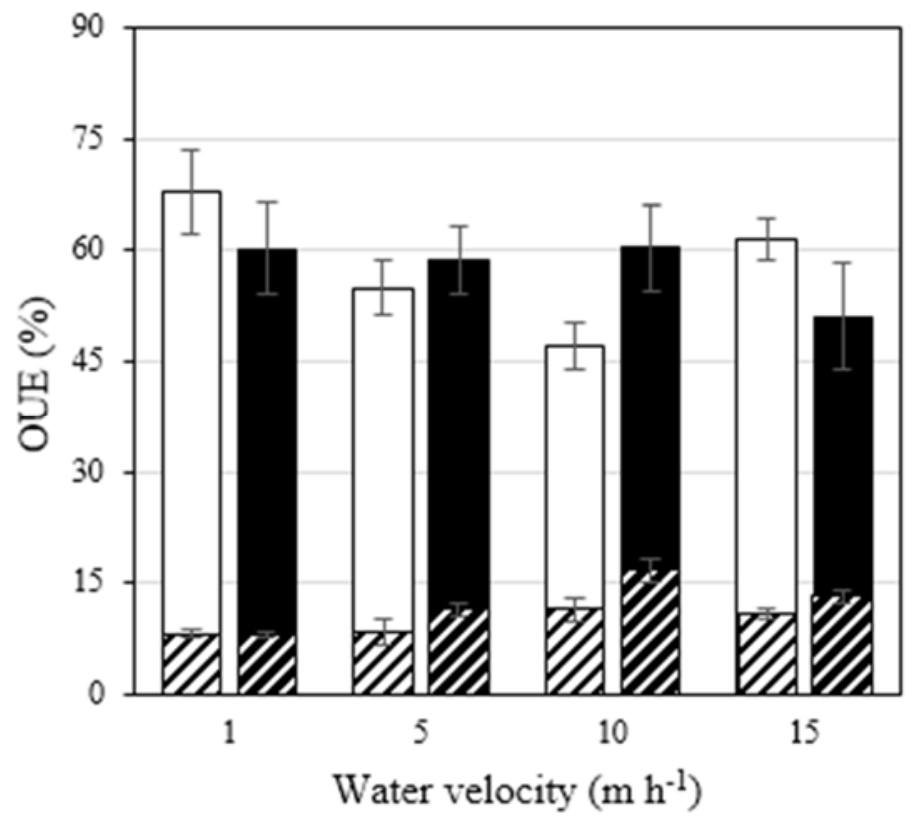

Figure 8. Oxygen Utilization Efficiency (\%) from supplied oxygen (OUE) (striped) and from transferred oxygen ( $\mathrm{OUE}_{\mathrm{t}}$ ) (plain), in R1 (white background) and in R2 (black background) at the tested water velocities. Error bars represent $95 \%$ confidence intervals of the mean. 


\subsection{Nitrification performance}

Nitrification performance in this work is referred to membrane surface (SNR in $\mathrm{g} \mathrm{NH}_{4}-\mathrm{N}$ $\mathrm{m}^{-2} \mathrm{~d}^{-1}$ ) and to reactor volume (Volumetric Nitrification Rate (VNR) in $\mathrm{g} \mathrm{NH}_{4}-\mathrm{N} \mathrm{m}^{-3} \mathrm{~d}^{-1}$ ) and their values are graphically presented in Figure 9. Mean values and standard deviation of SNR and VNR are shown in Appendix section A.2. The significance values of the Student's T-tests and Tukey's HSD tests belonging to this analysis are shown in Appendix section A.3.
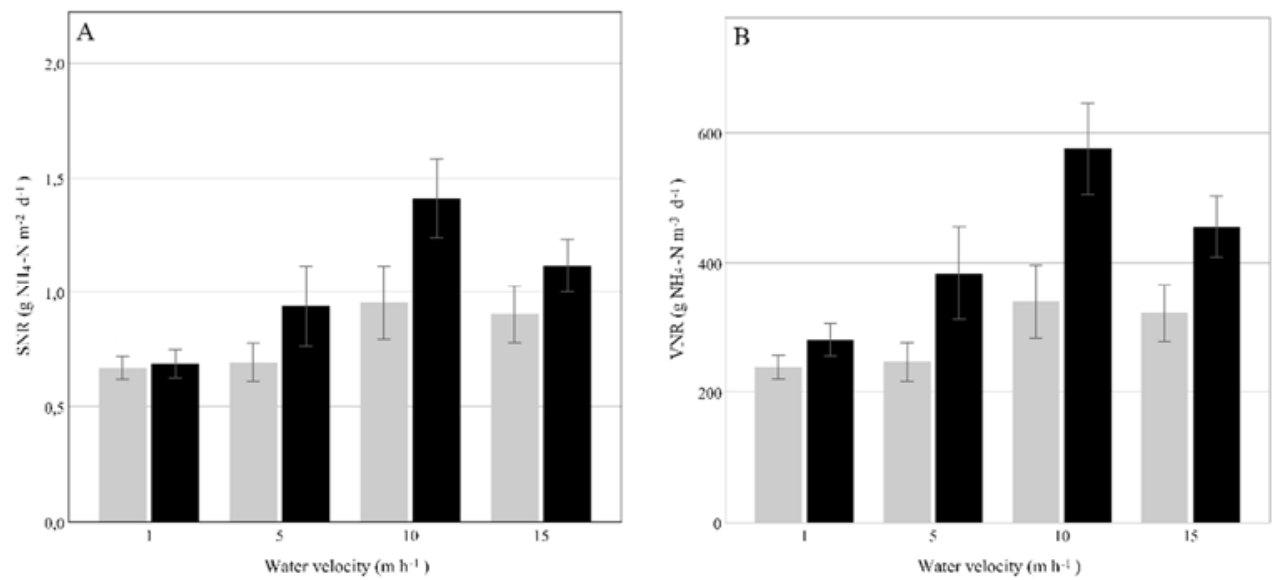

Figure 9. A. SNR $\left(\mathrm{g} \mathrm{NH}_{4}-\mathrm{N} \mathrm{m}^{-2} \mathrm{~d}^{-1}\right)$ and $\mathbf{B}$. VNR $\left(\mathrm{g} \mathrm{NH}_{4}-\mathrm{N} \mathrm{m}^{-3} \mathrm{~d}^{-1}\right)$ for the traditional (white) and the innovative (black) configurations at the tested velocities. Error bars represent $95 \%$ confidence intervals of the mean.

For all the cases tested, SNR is higher in the compact system that in the traditional system, although at low water velocity $\left(1 \mathrm{~m} \mathrm{~h}^{-1}\right)$ differences are not significant. At $5 \mathrm{~m} \mathrm{~h}^{-1}$ significant differences appear between both configurations and at 10 and $15 \mathrm{~m} \mathrm{~h}^{-1}$ the differences are highly significant. The most significant differences take place at $10 \mathrm{~m} \mathrm{~h}^{-1}$.

SNR and VNR were compared in pairs between different velocities within each configuration. Regarding R1, no differences are found between the two lowest velocities 
and between the two highest ones, while highly significant differences appear between the lowest and the two highest velocities and between the two intermediate ones. Significant differences occur between 5 and $15 \mathrm{~m} \mathrm{~h}^{-1}$. In $\mathrm{R} 2$ there are no statistically significant differences between 5 and $15 \mathrm{~m} \mathrm{~h}^{-1}$, but there exist highly significant differences between all the other couples, except between 1 and $15 \mathrm{~m} \mathrm{~h}^{-1}$, that are only significant. According to these results, it can be said that $10 \mathrm{~m} \mathrm{~h}^{-1}$ is the optimum water velocity for both configurations.

Accordingly to OTR, SNR and VNR also decreased at the highest water velocity tested, although this trend was statistically noticeable only in the case of the innovative configuration, in which VNR dropped to $79 \%$ of its value at $10 \mathrm{~m} \mathrm{~h}^{-1}$. In the case of the traditional configuration it dropped to $95 \%$.

When the nitrification capability is referred to the reactor volume, differences between both configurations at different velocities are always highly significant $(\alpha<0.006)$. Since the compact system holds less volume than the traditional one due to the higher membrane specific surface, the difference between both configurations is more remarkable when referring to volume. In other words, the improvement in mass transfer is noticeable when comparing SNR but is more accentuated when referring to occupied volume.

VNR reached in this experimentation are exceptionally high for MABR reactors. As shown in Table 1, in previous work on nitrification with MABR, similar or higher VNR are only found when using pure oxygen as gas phase (Hwang, Cicek and Oleszkiewicz, 2009b; Brindle et al., 1998). Higher SNR has been reached (Hwang, Cicek and Oleszkiewicz, 2009a; Syron, 2015 b) but using much lower membrane specific surfaces, thus resulting in lower VNR. In order to reach a sustainable process, air as gas phase is advisable. In addition, pressure should be maintained at low values in order to take advantage of a low energy consuming technology like MABR. Keeping this in mind, the herein proposed configuration overcomes former well-known mass transfer drawbacks, allowing reaching 
VNR comparable to well-established technologies.

SNR and VNR results are coherent with flow pattern and oxygen transfer experiments. Conditions providing more proper flow patterns and higher oxygen transfer rates in clean water provided also better nitrification performance. In tracer tests in presence of biomass, the velocities of 1 and $15 \mathrm{~m} \mathrm{~h}^{-1}$ gave place to a sharp peak in the tracer concentration in both $\mathrm{R} 1$ and R2, but at $15 \mathrm{~m} \mathrm{~h}^{-1}$ OTR was significantly higher than at $1 \mathrm{~m} \mathrm{~h}^{-1}$, thus providing better biological behaviour. Between 5 and $10 \mathrm{~m} \mathrm{~h}^{-1}$, the peak in tracer concentration in the traditional configuration was sharper at $10 \mathrm{~m} \mathrm{~h}^{-1}$, and accordingly differences in SNR between both configurations were more significant at $10 \mathrm{~m} \mathrm{~h}^{-1}$ than at $5 \mathrm{~m} \mathrm{~h}^{-1}$. The best results occurred at $10 \mathrm{~m} \mathrm{~h}^{-1}$ in the innovative configuration, whose tracer concentration curve was very close to a fully mixed tank's one and whose OTR in clean water was higher than at 1 and $5 \mathrm{~m} \mathrm{~h}^{-1}$ when it is measured in the gas phase, and similar or higher than at 15 $\mathrm{m} \mathrm{h}^{-1}$ when it is measured in the bulk water.

During the whole experimentation, average TSS in the effluent was $17 \pm 10 \mathrm{mg} \mathrm{L}^{-1}$. After finishing the experimental campaign the membranes were extracted from the reactor and TSS remaining in the water inside the vessel were measured. TSS concentration was 345.76 $\mathrm{mg} \mathrm{L}{ }^{-1}$ with an $\mathrm{SVI}_{30}$ of $56.97 \mathrm{~mL} \mathrm{~g}^{-1}$. As hypothesized, the membrane bed is able to retain a considerable amount of solids, so further research to discern the role of biofilm and entrapped biomass is the next step to consolidate the advantages of this technology. Its potential as filter avoiding the need for secondary clarifier may be exploited, determining its capacity without compromising its nitrogen removal efficiency and the need for periodically backwashing.

\section{CONCLUSIONS}

An innovative MABR configuration aimed at mass transfer enhancement was assessed through tracer-response tests, oxygenation tests and biological experimentation for nitrification. Results in terms of flow pattern, oxygen mass transfer and nitrification 
performance were compared with the same in a traditional configuration.

According to this work, the assessment of only OTR is not enough as method to evaluate and predict the performance of a configuration. However, oxygen transfer rate determination in the gas phase together with flow pattern characterization in clean water tests proved to give valuable information to predict the biological performance in nitrifying MABRs.

The novel configuration, based on random membrane distribution occupying the whole cross section of the reactor, enhanced the flow pattern at the intermediate water flow rates tested $\left(5\right.$ and $\left.10 \mathrm{~m} \mathrm{~h}^{-1}\right)$ compared to the traditional configuration.

The reduced occurrence of short-circuits in the innovative MABR resulted in a considerable improvement (up to $69.2 \%$ ) of specific and volumetric nitrification rates. Exceptionally high VNR for MABR were achieved, which are comparable to well-established technologies and 4.4 times more energy efficient than systems aerated by diffusers.

\section{Acknowledgements}

The Spanish Ministry of Economy and Competitiveness partially funded this research through the Network of Excellence RedNOVEDAR (CTQ2016-81979-REDC) and the project PBi2 (CTM2012-36227), the latter being co-financed by the European Regional Development Fund (FEDER). R. Díez-Montero would like to thank the Spanish Ministry of Industry and Economy for his research grant [FJCI-2016-30997].

\section{REFERENCES}

1. Ahmadi Motlagh, A. R., Voller, V. R., Semmens, M. J. 2006. Advective flow through membrane-aerated biofilms: Modeling results. Journal of Membrane Science 273 (1-2), 143-151, 10.1016/j.memsci.2005.12.039. 
2. ASCE (American Society of Civil Engineers) 1994. ASCE Standard-Measurement of Oxygen Transfer in Clean Water.

3. Barwal, A. and Chaudhary, R. 2014. To study the performance of biocarriers in moving bed biofilm reactor (MBBR) technology and kinetics of biofilm for retrofitting the existing aerobic treatment systems: A review. Reviews in Environmental Science and Biotechnology 13 (3), 285-299, 10.1007/s11157-0149333-7.

4. Brindle, K., Stephenson, T., Semmens, M. J. 1998. Nitrification and oxygen utilisation in a membrane aeration bioreactor. Journal of Membrane Science 144 (1-2), 197-209, 10.1016/S0376-7388(98)00047-7.

5. Costello, M. J., Fane, A. G., Hogan, P. A., Schofield, R. W. 1993. The effect of shell side hydrodynamics on the performance of axial flow hollow fibre modules. Journal of Membrane Science 80 (1), 1-11, 10.1016/0376-7388(93)85127-I.

6. Côté, P., Bersillon, J., Huyard, A. 1989. Bubble-free aeration using membranes: mass transfer analysis. Journal of Membrane Science 47 (1-2), 91-106, $10.1016 / \mathrm{S} 0376-7388(00) 80862-5$.

7. da Silva, T.S., Matsumoto, T., dos Anjos, M.L., Albertin, L.L. 2018 Organic Matter Removal in a Membrane-Aerated Biofilm Reactor. Journal of Environmental Engineering 144(8): 04018057, 10.1061/(ASCE)EE.1943-7870.0001393

8. Downing, L. S. and Nerenberg, R. 2008. Effect of oxygen gradients on the activity and microbial community structure of a nitrifying, membrane-aerated biofilm. Biotechnology and bioengineering 101 (6), 1193-1204, 10.1002/bit.22018. 
9. Hwang, J. H., Cicek, N., Oleszkiewicz, J. 2009a. Effect of loading rate and oxygen supply on nitrification in a non-porous membrane biofilm reactor. Water research 43 (13), 3301-3307, 10.1016/j.watres.2009.04.034.

10. Hwang, J. H., Cicek, N., Oleszkiewicz, J. A. 2009b. Long-term operation of membrane biofilm reactors for nitrogen removal with autotrophic bacteria. Water Science and Technology 60 (9), 2405-2412, 10.2166/wst.2009.624.

11. Kavousi, F., Syron, E., Semmens, M., Casey, E. 2016. Hydrodynamics and gas transfer performance of confined hollow fibre membrane modules with the aid of computational fluid dynamics. Journal of Membrane Science 513, 117-128, 10.1016/j.memsci.2016.04.038.

12. Metcalf, L. and Eddy, H. P. (2004) Wastewater Engineering. Treatment and reuse. McGraw Hill.

13. Nerenberg, R. 2016. The membrane-biofilm reactor (MBfR) as a counterdiffusional biofilm process. Current Opinion in Biotechnology 38, 131-136, http://dx.doi.org/10.1016/j.copbio.2016.01.015.

14. Osa, J., Eguia, E., Vidart, T., Jacome, A., Lorda, I., Amieva, J., Tejero, I., 1997. Wastewater treatment with biofilm membrane reactors. In: Conference on Advanced Wastewater Treatment Processes. Leeds University, Leeds, UK, 1997.

15. Pellicer-Nàcher, C., Domingo-Félez, C., Lackner, S., Smets, B. F. 2013. Microbial activity catalyzes oxygen transfer in membrane-aerated nitritating biofilm reactors. Journal of Membrane Science 446, 465-471, 10.1016/j.memsci.2013.06.063.

16. Perez-Calleja, P., Aybar, M., Picioreanu, C., Esteban-Garcia, A. L., Martin, K. J., Nerenberg, R. 2017. Periodic venting of MABR lumen allows high removal rates 
and high gas-transfer efficiencies. Water research 121, 349-360, 10.1016/j.watres.2017.05.042.

17. Plascencia-Jatomea, R., Almazán-Ruiz, F. J., Gómez, J., Rivero, E. P., Monroy, O., González, I. 2015. Hydrodynamic study of a novel membrane aerated biofilm reactor (MABR): Tracer experiments and CFD simulation. Chemical Engineering Science 138, 324-332, 10.1016/j.ces.2015.08.004.

18. Soreanu, G., Lishman, L., Dunlop, S., Behmann, H., Seto, P. 2010. An assessment of oxygen transfer efficiency in a gas permeable hollow fibre membrane biological reactor. Water Science and Technology 61 (5), 1165-1171, 10.2166/wst.2010.877.

19. Syron E. and Byrne W. 2015. A Membrane Aerated Biofilm Reactor (MABR), Patent $n^{\circ}$. WO 2015/132291A1

20. Syron E. and Casey E. 2014. Reducing the energy consumption of aerobic sewage treatment by removing the bubbles. 2nd IWA Specialized International Conference ecoSTP2014 EcoTechnologies for Wastewater Treatment Technical, Environmental \& Economic Challenges Verona, Italy | 23-27 June 2014.

21. Syron, E., Semmens, M. J., Casey, E. 2015. Performance analysis of a pilot-scale membrane aerated biofilm reactor for the treatment of landfill leachate. Chemical Engineering Journal 273, 120-129, 10.1016/j.cej.2015.03.043.

22. Terada, A., Hibiya, K., Nagai, J., Tsuneda, S., Hirata, A. 2003. Nitrogen removal characteristics and biofilm analysis of a membrane-aerated biofilm reactor applicable to high-strength nitrogenous wastewater treatment. Journal of Bioscience and Bioengineering 95 (2), 170-178, 10.1263/jbb.95.170.

23. Wang, R., Xiao, F., Wang, Y., Lewandowski, Z. 2016. Determining the optimal transmembrane gas pressure for nitrification in membrane-aerated biofilm reactors 
based on oxygen profile analysis. Applied Microbiology and Biotechnology 100 (17), 7699-7711, 10.1007/s00253-016-7553-1.

24. Wang, R., Dai, S., Tang, Y., Zhao, J. 2012. Hydrodynamic characteristics assessment and modeling of a novel membrane-aerated reactor. Advanced Materials Research 516-517, 763-768, 10.4028/www.scientific.net/AMR.516517.763.

25. Wei, X., Li, B., Zhao, S., Qiang, C., Zhang, H., Wang, S. 2012. COD and nitrogen removal in facilitated transfer membrane-aerated biofilm reactor (FT-MABR). Journal of Membrane Science 389, 257-264, 10.1016/j.memsci.2011.10.038.

26. $\mathrm{Wu}, \mathrm{J}$. and Chen, V. 2000. Shell-side mass transfer performance of randomly packed hollow fiber modules. Journal of Membrane Science 172 (1-2), 59-74, $10.1016 / \mathrm{S} 0376-7388(00) 00318-5$. 


\section{APPENDIX}

\section{A.1. Oxygen transfer and utilization efficiency with bare and colonized membranes}

The tables below show the significance level $(\alpha)$ resulting from the statistical analysis for means comparison between two groups of measures. Two asterisks on a $\alpha$ value means that there exists highly significance difference between both groups, one asterisk means that there exists significance difference between both groups, while no asterisks mean that there is not statistically significance difference.

\section{A.1.1. Comparison of OTR between $R 1$ and $R 2$ at different velocities.}

The table shows the significance values $(\alpha)$ of Student's T-test.

\begin{tabular}{|c|c|}
\hline Velocity $\left(\mathrm{m} \mathrm{s}^{-1}\right)$ & $\alpha$ \\
\hline 1 & 0.188 \\
\hline 5 & 0.053 \\
\hline 10 & 0.222 \\
\hline 15 & $0.002^{* *}$ \\
\hline
\end{tabular}

A.1.2. Comparison of OTR between pairs of velocities in R1.

The table shows the significance values of post-hoc Tukey's HSD test.

\begin{tabular}{|c|c|c|c|c|}
\hline $\begin{array}{c}\text { Velocity } \\
\left(\mathrm{m} \mathrm{s}^{-1}\right)\end{array}$ & 1 & 5 & 10 & 15 \\
\hline 1 & & 0.058 & $0.000^{* *}$ & $0.002 * *$ \\
\hline 5 & & & $0.000^{* *}$ & 0.083 \\
\hline 10 & & & & $0.001 * *$ \\
\hline 15 & & & & \\
\hline
\end{tabular}

A.1.3. Comparison of OTR between pairs of velocities in R2.

The table shows the significance values of post-hoc Tukey's HSD test.

\begin{tabular}{|c|c|c|c|c|}
\hline $\begin{array}{c}\text { Velocity } \\
\left(\mathrm{m} \mathrm{s}^{-1}\right)\end{array}$ & 1 & 5 & 10 & 15 \\
\hline 1 & & 0.107 & $0.001 * *$ & $0.002 * *$ \\
\hline 5 & & & $0.014^{*}$ & $0.045^{*}$ \\
\hline 10 & & & & 0.822 \\
\hline 15 & & & & \\
\hline
\end{tabular}

\section{A.1.4. Comparison of $\mathrm{OUE}_{\mathrm{t}}$ between $\mathrm{R} 1$ and $\mathrm{R} 2$ at different velocities.}

The table shows the significance values $(\alpha)$ of Student's T-test. 


\begin{tabular}{|c|c|}
\hline Velocity $\left(\mathrm{m} \mathrm{s}^{-1}\right)$ & $\alpha$ \\
\hline 1 & 0.269 \\
\hline 5 & 0.569 \\
\hline 10 & 0.068 \\
\hline 15 & 0.165 \\
\hline
\end{tabular}

A.1.5. Comparison of $\mathrm{OUE}_{\mathrm{t}}$ between pairs of velocities in R1.

The table shows the significance values of post-hoc Tukey's HSD test.

\begin{tabular}{|c|c|c|c|c|}
\hline $\begin{array}{c}\text { Velocity } \\
\left(\mathrm{m} \mathrm{s}^{-1}\right)\end{array}$ & 1 & 5 & 10 & 15 \\
\hline 1 & & 0.226 & $0.037^{*}$ & 0.740 \\
\hline 5 & & & 0.594 & 0.704 \\
\hline 10 & & & & 0.158 \\
\hline 15 & & & & \\
\hline
\end{tabular}

A.1.6. Comparison of $\mathrm{OUE}_{\mathrm{t}}$ between pairs of velocities in $\mathrm{R} 2$.

The table shows the significance values of post-hoc Tukey's HSD test.

\begin{tabular}{|c|c|c|c|c|}
\hline $\begin{array}{c}\text { Velocity } \\
\left(\mathrm{m} \mathrm{s}^{-1}\right)\end{array}$ & 1 & 5 & 10 & 15 \\
\hline 1 & & 0.926 & 1 & 0.202 \\
\hline 5 & & & 0.940 & 0.434 \\
\hline 10 & & & & 0.192 \\
\hline 15 & & & & \\
\hline
\end{tabular}


A.2. Mean values \pm standard deviation of SNR $\left(\mathrm{g} \mathrm{m}^{-2} \mathrm{~d}^{-1}\right)$ and $\operatorname{VNR}\left(\mathrm{g} \mathrm{m}^{-3} \mathrm{~d}^{-1}\right)$ for the traditional and the compact configurations at the tested velocities.

\begin{tabular}{|c|c|c|c|c|}
\hline \multirow[b]{2}{*}{$\begin{array}{c}\text { Water } \\
\text { velocity } \\
\left(\mathrm{m} \mathrm{h}^{-1}\right)\end{array}$} & \multicolumn{2}{|c|}{$\mathrm{SNR}\left(\mathrm{g} \mathrm{NH}_{4}-\mathrm{N} \mathrm{m}^{-2} \mathrm{~d}^{-1}\right)$} & \multicolumn{2}{|c|}{$\operatorname{VNR}\left(\mathrm{g} \mathrm{NH}_{4}-\mathrm{N} \mathrm{m}^{-3} \mathrm{~d}^{-1}\right)$} \\
\hline & $\begin{array}{l}\text { Traditional } \\
\text { configuration }\end{array}$ & $\begin{array}{c}\text { Compact } \\
\text { configuration }\end{array}$ & $\begin{array}{c}\text { Traditional } \\
\text { configuration }\end{array}$ & $\begin{array}{c}\text { Compact } \\
\text { configuration }\end{array}$ \\
\hline 1 & $0.670 \pm 0.049$ & $0.688 \pm 0.059$ & $238.54 \pm 17.44$ & $280.84 \pm 23.88$ \\
\hline 5 & $0.693 \pm 0.080$ & $0.942 \pm 0.168$ & $246.77 \pm 28.46$ & $383.86 \pm 68.44$ \\
\hline 10 & $0.956 \pm 0.153$ & $1.411 \pm 0.165$ & $340.34 \pm 54.34$ & $575.84 \pm 67.17$ \\
\hline 15 & $0.904 \pm 0.118$ & $1.118 \pm 0.110$ & $321.95 \pm 42.17$ & $455.94 \pm 44.82$ \\
\hline
\end{tabular}

\section{A.3. SNR (g NH $\left.4-\mathrm{N} \mathrm{m}^{-2} \mathrm{~d}^{-1}\right)$ and VNR $\left(\mathrm{g} \mathrm{NH}_{4}-\mathrm{N} \mathrm{m}^{-3} \mathrm{~d}^{-1}\right)$ results.}

The tables below show the significance level $(\alpha)$ resulting from the statistical analysis for means comparison between two groups of measures. Two asterisks on a $\alpha$ value means that there exists highly significance difference between both groups, one asterisk means that there exists significance difference between both groups, while no asterisks mean that there is not statistically significance difference.

\section{A.3.1. Comparison of SNR between R1 and R2 at different velocities.}

The table shows the significance values $(\alpha)$ of Student's T-test.

\begin{tabular}{|c|c|}
\hline Velocity $\left(\mathrm{m} \mathrm{s}^{-1}\right)$ & $\alpha$ \\
\hline 1 & 0.563 \\
\hline 5 & $0.013^{*}$ \\
\hline 10 & $0.001^{* *}$ \\
\hline 15 & $0.009^{* *}$ \\
\hline
\end{tabular}




\section{A.3.2. Comparison of SNR between pairs of velocities in R1.}

The table shows the significance values of post-hoc Tukey's HSD test.

\begin{tabular}{|c|c|c|c|c|}
\hline $\begin{array}{c}\text { Velocity } \\
\left(\mathrm{m} \mathrm{s}^{-1}\right)\end{array}$ & 1 & 5 & 10 & 15 \\
\hline 1 & & 0.982 & $0.001 * *$ & $0.006^{* *}$ \\
\hline 5 & & & $0.002^{* *}$ & $0.014^{*}$ \\
\hline 10 & & & & 0.838 \\
\hline 15 & & & & \\
\hline
\end{tabular}

\section{A.3.3. Comparison of SNR between pairs of velocities in R2.}

The table shows the significance values of post-hoc Tukey's HSD test.

\begin{tabular}{|c|c|c|c|c|}
\hline $\begin{array}{c}\text { Velocity } \\
\left(\mathrm{m} \mathrm{s}^{-1}\right)\end{array}$ & 1 & 5 & 10 & 15 \\
\hline 1 & & $0.018^{*}$ & $0.000^{* *}$ & $0.000^{* *}$ \\
\hline 5 & & & $0.000^{* *}$ & 0.131 \\
\hline 10 & & & & $0.005^{* *}$ \\
\hline 15 & & & & \\
\hline
\end{tabular}

\section{A.3.4. Comparison of VNR between $\mathrm{R} 1$ and $\mathrm{R} 2$ at different velocities.}

The table shows the significance values $(\alpha)$ of Student's T-test.

\begin{tabular}{|c|c|}
\hline Velocity $\left(\mathrm{m} \mathrm{s}^{-1}\right)$ & $\alpha$ \\
\hline 1 & $0.006^{* *}$ \\
\hline 5 & $0.003^{* *}$ \\
\hline 10 & $0.000^{* *}$ \\
\hline 15 & $0.000^{* *}$ \\
\hline
\end{tabular}

\section{A.3.5. Comparison of VNR between pairs of velocities in R1.}

The table shows the significance values of post-hoc Tukey's HSD test.

\begin{tabular}{|c|c|c|c|c|}
\hline $\begin{array}{c}\text { Velocity } \\
\left(\mathrm{m} \mathrm{s}^{-1}\right)\end{array}$ & 1 & 5 & 10 & 15 \\
\hline 1 & & 0.982 & $0.001^{* *}$ & $0.006^{* *}$ \\
\hline 5 & & & $0.002^{* *}$ & $0.014^{*}$ \\
\hline 10 & & & & 0.838 \\
\hline 15 & & & & \\
\hline
\end{tabular}


A.3.6. Comparison of VNR between pairs of velocities in R2.

The table shows the significance values of post-hoc Tukey's HSD test.

\begin{tabular}{|c|c|c|c|c|}
\hline $\begin{array}{c}\text { Velocity } \\
\left(\mathrm{m} \mathrm{s}^{-1}\right)\end{array}$ & 1 & 5 & 10 & 15 \\
\hline 1 & & $0.018^{*}$ & $0.000^{* *}$ & $0.000^{* *}$ \\
\hline 5 & & & $0.000^{* *}$ & 0.131 \\
\hline 10 & & & & $0.005^{* *}$ \\
\hline 15 & & & & \\
\hline
\end{tabular}

